\title{
Characterization of Modified Silica Powders by Fourier Transform Infrared Spectroscopy and Cross-Polarization Magic Angle Spinning NMR
}

\author{
J. W. DE HAAN,* H. M. VAN DEN BOGAERT, $\dagger$ J. J. PONJEÉ, $\dagger$ \\ AND L. J. M. VAN DE VEN* \\ *Laboratory of Instrumental Analysis, Department of Chemistry, Eindhoven University of Technology, P.O. Box \\ 513, $5600 \mathrm{MB}$ Eindhoven, and $\dagger$ Philips Research Laboratories, $5600 \mathrm{JA}$ Eindhoven, The Netherlands
}

Received February 25, 1985; accepted August 7, 1985

\begin{abstract}
Silica gel and Cab-O-Sil were chemically modified (silylated) with 3-aminopropyltriethoxysilane and 3-methacryloxypropyltrimethoxysilane under carefully controlled conditions. Subsequently the products were investigated by elemental analysis, Fourier transform IR spectroscopy, and ${ }^{13} \mathrm{C}$ and ${ }^{29} \mathrm{Si}$ crosspolarization magic angle spinning NMR (CP-MAS NMR). The influence of the reaction conditions of the silylation and the effect of subsequent heat treatment and water addition were studied. The resulting differences shed new light on the combined effects of reaction conditions and silica surface structures on the course of the reactions. Some assignments of ${ }^{29} \mathrm{Si}$ NMR signals to specific structures were confirmed, while in one case a reassignment was proposed. 1986 Academic Press, Inc.
\end{abstract}

\section{INTRODUCTION}

Although there are many reports in the literature concerning silane coupling agents on glass or silica (1), little attention has been paid to the nature of the bonds between the surface and the silane coupling agents until recently (2). In addition to the physisorption of molecules of the silane coupling agents onto the silica surface, covalent bonds between substrate and silane coupling agent are usually postulated. Although covalent attachments of trifunctional silanes to silica can be formally described as mono-, bi-, or tridentate linkages, there is, apart from recently published NMR work (2), no analytical evidence reported in the literature to suggest which of these representations are appropriate. Nevertheless, all three notations are in use (3-5). Previous work concerning the binding of silanes to substrates has been performed mainly by vibrational spectroscopy (6-8). One of the problems often encountered with this method concerns the difficulty in the identification of different $\mathrm{OH}$ and $\mathrm{SiO}$ bonds. More specific information may be obtained by high-resolution ${ }^{13} \mathrm{C}$ and ${ }^{29} \mathrm{Si}$ cross-polarization magic angle spinning
NMR (CP-MAS NMR). Examples of the use of ${ }^{13} \mathrm{C}$ NMR on surface modification problems related to those discussed here have been presented by Chiang et al. (9) and by Leyden et al. $(10,11)$. Systematic NMR results, for both ${ }^{13} \mathrm{C}$ and ${ }^{29} \mathrm{Si}$, have been reported by Maciel and co-workers $(2,12-16)$. Much qualitative information was given including some structural assignments, although some of these were reported as preliminary.

The present paper reports the reactions, under carefully controlled experimental conditions, of 3-aminopropyltriethoxysilane (APS) and of 3-methacryloxypropyltrimethoxysilane (MPS) with porous (silica gel) and nonporous (Cab-O-Sil) silica powders.<smiles>C=C(C)C(=O)OCCC[Si](C)(OC)OC</smiles> 
These materials have different physical and chemical characteristics (see Methods). In this investigation we have observed differences in the relative numbers of silanediol (geminal) and silanol (one hydroxyl group) sites. Modification of both powders has been described before $(2,10,11)$, but not in one set of experiments under identical conditions, allowing comparison of the results.

Elemental analysis, FT-IR and ${ }^{29} \mathrm{Si}-$ and ${ }^{13} \mathrm{C}$ CP-MAS NMR have been applied to study the nature of the bonds between the silane coupling agents and the silica. The influence of heat treatment and water addition at different stages of the process has been studied. The resulting differences in surface structures will be related to the sequence of heating and water treatment on one hand and the differences between silica gel and Cab-O-Sil on the other hand. During this investigation many of the earlier ${ }^{29} \mathrm{Si}$ NMR assignments by Maciel et al. have been confirmed, in a few cases additional assignments are proposed, and in one particular case a reassignment is preferred.

\section{METHODS}

Silica gel with an average pore diameter of $50 \mathrm{~nm}$, a mean particle size of $58 \mu \mathrm{m}$, and a specific surface area of $600 \mathrm{~m}^{2} / \mathrm{g}$ was purchased from Alfa Products (Danvers, Mass.). A nonporous fumed silica (Cab-O-Sil) with a mean particle size of $0.007 \mu \mathrm{m}$ and a specific surface area of $400 \mathrm{~m}^{2} / \mathrm{g}$ was obtained from Cabot Corporation (Tuscold, Ill.). According to information from the manufacturers the porous silica surface contains 4.8 to 5.2 hydroxyl groups $/ \mathrm{nm}^{2}$ and the nonporous silica surface, 3.5 to 4.5 hydroxyl groups $/ \mathrm{nm}^{2}$. Thus the resulting ratio in hydroxyl concentrations of silica gel and Cab-O-Sil amounts to 1.9.

Porous silica gel was dried for $48 \mathrm{~h}$ at $190^{\circ} \mathrm{C}$. 3-Aminopropyltriethoxysilane and 3methacryloxypropyltrimethoxysilane were purchased from Aldrich and distilled at reduced pressure in an argon gas atmosphere before use. Toluene and biphenyl were dried with molecular sieves ( $4 \AA$ ). The solvents contain $₹ 1$ ppm of water.

\section{Sample Preparation}

As an example, the preparation of the first five samples is described.

Sample 1. To a solution of $2.5 \mathrm{~g}$ APS in 150 $\mathrm{ml}$ toluene $4.5 \mathrm{~g}$ porous silica gel was added. The mixture was refluxed for $1 \mathrm{~h}$ while stirring. The modified silica gel was filtered off, rinsed three times with toluene, and dried at $100^{\circ} \mathrm{C}$. All operations were carried out in a dry argon atmosphere and all glass equipment was dried in an oven at $175^{\circ} \mathrm{C}$.

Sample 2. One gram of sample 1 was heated for $1 \mathrm{~h}$ at $200^{\circ} \mathrm{C}$ in an argon atmosphere.

Sample 3. Two grams of sample 1 was stirred with $50 \mathrm{ml}$ water at room temperature for $2 \mathrm{~h}$. After it was filtered and rinsed with water the sample was dried at $100^{\circ} \mathrm{C}$ for $1 \mathrm{~h}$ in an argon atmosphere.

Sample 4. One gram of sample 3 was heated for $1 \mathrm{~h}$ at $200^{\circ} \mathrm{C}$ in an argon atmosphere.

Sample 5. To a solution of $1 \mathrm{~g}$ APS in 100 $\mathrm{ml}$ water $3 \mathrm{~g}$ porous silica gel was added. After it was stirred for $1 \mathrm{~h}$ at room temperature the modified silica gel was filtered off, rinsed with water, and dried at $100^{\circ} \mathrm{C}$ for $1 \mathrm{~h}$ in an argon atmosphere.

Samples 6-14 were prepared in a similar way. The reaction conditions are listed in $\mathrm{Ta}$ ble I.

The results of the elemental analysis and the surface coverage are given in Table II.

\section{Instruments}

Infrared spectra were obtained with a Nicolet 7199 Fourier transform infrared spectrometer. Samples were pressed either into a $\mathrm{KBr}$ disk or into thin pellets with a diameter of $13 \mathrm{~mm}$ or alternatively mulled in Nujol or polychlorotrifluoroethylene. ${ }^{29} \mathrm{Si}$ and ${ }^{13} \mathrm{C} \mathrm{CP}$ MAS NMR spectra were obtained on a Bruker CXP 300 spectrometer at 59.63 and 75.476 $\mathrm{MHz}$, respectively. The compounds were spun at ca. $3.8 \mathrm{kHz}$ using Delrin (for ${ }^{29} \mathrm{Si} \mathrm{NMR}$ ) or boron nitride (for ${ }^{13} \mathrm{C}$ NMR) Andrew-type rotors. The spectral width was $20 \mathrm{kHz}$. Pulse interval times were $1 \mathrm{~s}\left({ }^{29} \mathrm{Si} \mathrm{NMR}\right)$ or $3 \mathrm{~s}\left({ }^{13} \mathrm{C}\right.$ NMR). Single contacts were used with contact 
TABLE I

Preparation of Samples

\begin{tabular}{|c|c|c|c|c|}
\hline Sample & Type of silica & Reagent & Reaction solvent & $\begin{array}{c}\text { Drying } \\
\text { temperature } \\
\left({ }^{\circ} \mathrm{C}\right)\end{array}$ \\
\hline 1 & Silica gel & APS & Toluene & 100 \\
\hline 2 & Silica gel & APS & Toluene & 200 \\
\hline 3 & Silica gel & APS & Toluene/water treated & 100 \\
\hline 4 & Silica gel & APS & Toluene/water treated & 200 \\
\hline 5 & Silica gel & APS & Water & 100 \\
\hline 6 & Silica gel & APS & Water & 200 \\
\hline 7 & Cab-O-Sil & APS & Water & 100 \\
\hline 8 & Cab-O-Sil & APS & Water & 200 \\
\hline 9 & Cab-O-Sil & APS & Toluene & 100 \\
\hline 10 & Cab-O-Sil & APS & Toluene & 200 \\
\hline 11 & Silica gel & MPS & Toluene & 100 \\
\hline 12 & Silica gel & MPS & Toluene/water treated & 100 \\
\hline 13 & Silica gel & MPS & Biphenyl & 100 \\
\hline 14 & Silica gel & MPS & Biphenyl/water treated & 100 \\
\hline
\end{tabular}

times of $2 \mathrm{~ms}\left({ }^{29} \mathrm{Si}\right)$ or $5 \mathrm{~ms}\left({ }^{13} \mathrm{C}\right)$ which turned out to be reasonable compromises for our samples. Typically, 20,000 to 40,000 FIDs were accumulated in $1 \mathrm{~K}$ data points, which

TABLE II

Analysis of Samples 1-14

\begin{tabular}{rrrrr}
\hline Sample & $\begin{array}{c}\text { Carbon } \\
\text { content } \\
(\%)\end{array}$ & $\begin{array}{c}\text { Nitrogen } \\
\text { content } \\
(\%)\end{array}$ & $\begin{array}{c}\text { Carbon } \\
\text { nitrogen } \\
\text { ratio }\end{array}$ & $\begin{array}{c}\text { Surface } \\
\text { coverage } \\
\left(\mu \mathrm{mole} / \mathrm{m}^{2}\right)\end{array}$ \\
\hline 1 & 7.53 & 1.71 & 5.1 & 2.03 \\
2 & 6.60 & 1.72 & 4.5 & 2.03 \\
3 & 4.54 & 1.72 & 3.1 & 2.06 \\
4 & 4.26 & 1.65 & 3.0 & 1.96 \\
5 & 5.13 & 2.01 & 3.0 & 2.38 \\
6 & 5.28 & 2.07 & 3.0 & 2.49 \\
7 & 3.34 & 1.38 & 2.8 & 2.45 \\
8 & 3.45 & 1.44 & 2.8 & 2.56 \\
9 & 4.45 & 1.00 & 5.2 & 1.79 \\
10 & 3.94 & 1.02 & 4.5 & 1.81 \\
11 & 10.93 & & & 1.89 \\
12 & 10.30 & & & 2.04 \\
13 & 13.90 & & & 2.42 \\
14 & 13.60 & & & 2.38 \\
\hline
\end{tabular}

${ }^{a}$ The surface coverage of samples $1-10$ is calculated from the nitrogen content; for samples 11,13 , and 14 the surface coverage is based on the presence of a presumed average of one methoxy group and, for sample 12 , on the absence of methoxy groups. were zero filled to $8 \mathrm{~K}$ prior to transformation. All chemical shifts were referred to TMS.

\section{RESULTS AND DISCUSSION}

\section{a. Comparison of Silica Gel and Cab-O-Sil}

The untreated silica powders show simple infrared spectra with a very broad strong band between 1050 and $1200 \mathrm{~cm}^{-1}$, which can be assigned to the Si-O stretching mode. Additional bands are found at 960,800 , and 470 $\mathrm{cm}^{-1}$. The band at $960 \mathrm{~cm}^{-1}$, due to the Si$\mathrm{OH}$ stretching mode, can be used for diagnostic purposes in the modification process.

${ }^{29} \mathrm{Si}$ CP-MAS NMR spectra of the two materials are shown in Fig. 1. These spectra were obtained with the same number of pulses. Corrected for the different weights of samples they result in a total silanol [Si-OH and $\mathrm{Si}(\mathrm{OH})_{2}$ ] signal for silica gel about 2.2 times as large as that for Cab-O-Sil. This compares reasonably with the IR spectra and with information from the manufacturers. The ${ }^{29} \mathrm{Si}$ NMR spectra show that the relative populations of lone silanol groups $(\delta \simeq-101 \mathrm{ppm})$ and geminal silanediol groups $(\delta \simeq-91 \mathrm{ppm})$ differ widely for the two materials. For silica 


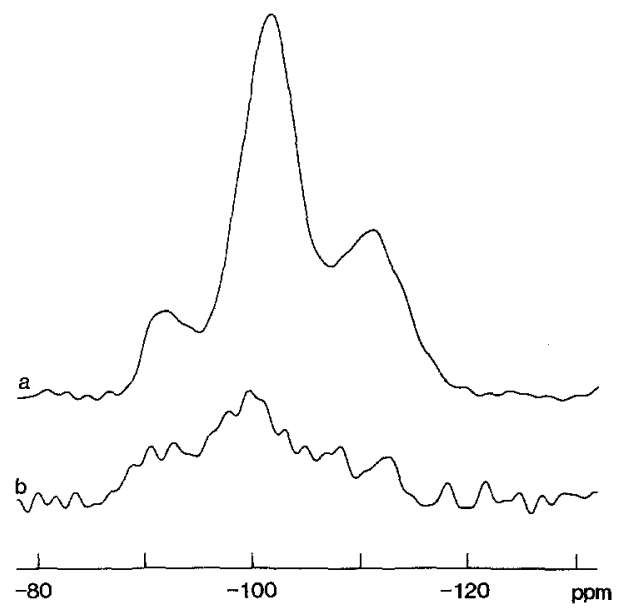

FIG. 1. ${ }^{29} \mathrm{Si}$ CP-MAS NMR spectra: (a) silica gel, (b) Cab-O-Sil.

gel the ratio of the band intensities of silanol to those of the silanediol groups is larger than 4.5; for Cab-O-Sil it is about 2.

\section{b. Derivatization of Silica Gel with APS in Toluene}

Due care was taken that both reactants and solvent were devoid of water. FT-IR and ${ }^{13} \mathrm{C}$ CP-MAS NMR spectra (Fig. 2a; Table III) independently showed that ethoxy groups were still present in sample 1.

According to IR analysis combined with elemental analysis (Table II sample 1) an average of one ethoxy group per silane unit is present in this reaction product. The reaction products of silica powders with APS have been widely studied by infrared spectroscopy (6-8). The infrared spectrum measured in the region from 1800 to $1300 \mathrm{~cm}^{-1}$ shows a strong $\mathrm{NH}_{2}$ deformation mode at $1600 \mathrm{~cm}^{-1}$ with weak absorptions at 1545 and $1473 \mathrm{~cm}^{-1}$, probably corresponding to the asymmetric and symmetric deformation modes of an $\mathrm{NH}_{3}^{+}$group. Bands observed at 1485, 1450, 1393, and 1368 $\mathrm{cm}^{-1}$ have been assigned to the ethoxy group. No attempts were made to obtain really quantitative results from ${ }^{13} \mathrm{C}$ NMR, as the crosspolarization characteristics differ considerably between the ethoxy- and the 3-aminopropyl carbon atoms. The ${ }^{29} \mathrm{Si}$ NMR spectrum showed signals at $-54,-59$, and $-66 \mathrm{ppm}$ (Table IV). Signals in the region from -52 to $-60 \mathrm{ppm}$ are usually assigned to silicon atoms connected via two oxygen atoms either to the surface or to the neighboring silanes, while the fourth group should be a hydroxy or methoxy group. In the present case, however, there are reasons to ascribe the signal at $-54 \mathrm{ppm}$ for samples 1 and 2 to a different structural group. A comparison of Maciel's results $(2,13)$ with those published by Bayer $e t$ al. (17) and results obtained by Claessens et al. (18) points to a shielding effect of about -4 ppm upon replacement of a methyl group in $\mathrm{Si}-\mathrm{CH}_{3}$ with an alkyl group. Whereas methoxy and hydroxy groups probably differ only slightly in their substituent effects on the ${ }^{29} \mathrm{Si}$ NMR chemical shift $(2,19)$, a shielding effect of about -5.5 ppm is observed in the present study for two ethoxy substituents with respect to two hydroxy substituents. This can perhaps be understood as two shielding $\gamma$ effects of the ethoxy-methyl groups on the central silicon atom (20). A similar conclusion can already be reached by comparing Maciel's chemical

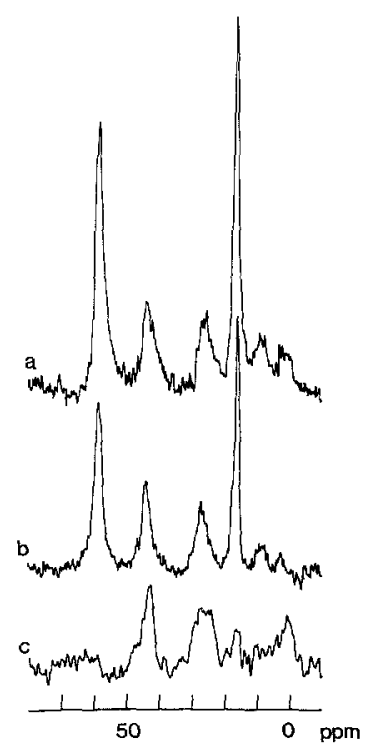

FIG. 2. ${ }^{13} \mathrm{C}$ CP-MAS NMR spectra: (a) derivatization product of silica gel with APS in toluene, (b) product after heating at $200^{\circ} \mathrm{C}$ in an $\mathrm{Ar}$ atmosphere, (c) product after water treatment. 
TABLE III

${ }^{13} \mathrm{C}$ CP-MAS NMR Spectral Data



shift for ${ }^{29} \mathrm{Si}$ nuclei in type II (Scheme 1) arrangements, carrying one hydroxy or two ethoxy groups $(2,19)$.

\section{TABLE IV}

${ }^{29} \mathrm{Si} \mathrm{CP-MAS} \mathrm{NMR} \mathrm{Spectral} \mathrm{Data}$

\begin{tabular}{|c|c|c|c|c|}
\hline \multirow{2}{*}{$\frac{\text { Sample }}{1}$} & \multicolumn{3}{|c|}{ Line position in ppm ( $\delta \mathrm{TMS})^{a, b}$} & \multirow{2}{*}{$\frac{\begin{array}{c}\text { Substituted surface } \\
\text { silanols }^{c}\end{array}}{0.27}$} \\
\hline & $-54(40)$ & $-59(55)$ & $-66(5)$ & \\
\hline 2 & $-53(5)$ & $-59(55)$ & $-66(40)$ & 0.35 \\
\hline 3 & & $-58(40)$ & $-66(60)$ & 0.27 \\
\hline 4 & & $-58(29)$ & $-66(71)$ & 0.34 \\
\hline 5 & & $-58(55)$ & $-67(45)$ & 0.30 \\
\hline 6 & & $-58(40)$ & $-67(60)$ & 0.30 \\
\hline 7 & & $-59(30)$ & $-67(70)$ & 0.23 \\
\hline 8 & & $-59(20)$ & $-66(80)$ & 0.26 \\
\hline 9 & $-54(20)$ & $-60(60)$ & $-66(20)$ & 0.28 \\
\hline 10 & $-48(25)$ & $-57(50)$ & $-66(25)$ & 0.44 \\
\hline 11 & $-48(30)$ & $-57(70)$ & & 0.14 \\
\hline 12 & $-48(25)$ & $-57(75)$ & & 0.18 \\
\hline 13 & $-49(10)$ & $-59(70)$ & $-67(20)$ & 0.30 \\
\hline 14 & -49 & -58 & -67 & 0.30 \\
\hline
\end{tabular}

${ }^{a}$ For assignment of silane signals, see Scheme 1 .

${ }^{b}$ Percentages, in parentheses, pertain to silane signals only.

${ }^{c}$ Area of silane ${ }^{29} \mathrm{Si}$ NMR signals divided by the total ${ }^{29} \mathrm{Si}$ NMR signal area (i.e., a measure for the number of substituted silanol sites of the silica).
The difference between one ethoxy group and one hydroxy group could not easily be observed in the present set of samples, however, with regard to signals of structures $I I$ and $\mathrm{V}$ near $-58 \mathrm{ppm}$. This may be due to small shift differences between the appropriate silicon atoms in structures II and V, causing signal overlap.

Nevertheless, considering the above-mentioned effects regarding the probable influence of two ethoxy groups instead of hydroxy groups and an alkyl chain instead of a methyl group, together with the extremely dry reaction conditions, we prefer to ascribe the $-53 \mathrm{ppm}$ ${ }^{29} \mathrm{Si}$ NMR signal to a structural group of type I (see Scheme 1). ${ }^{1}$ Similarly, the signals at -58 and at $-66 \mathrm{ppm}$ are assigned to the units II, II', III, IV, and V in the way indicated. For these latter two signals the displacements with respect to Maciel's assignments for similar

${ }^{1}$ Note added in proof. After this work was submitted two publications appeared $(21,22)$, also describing ${ }^{29} \mathrm{Si}$ NMR signals near $-50 \mathrm{ppm}$ to type I structural elements. 

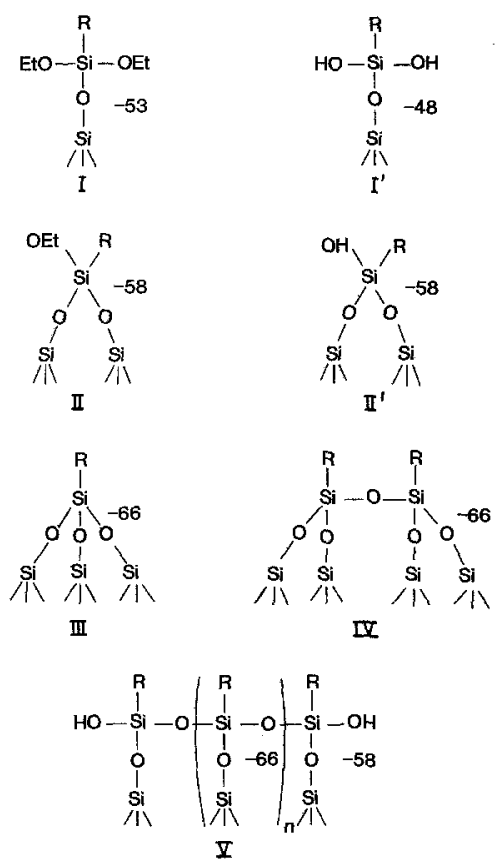

SCHEME 1

groups are about $-4 \mathrm{ppm}$ due to the presence of an alkyl group instead of a methyl group (see above), so that a reasonably consistent picture is obtained. The relative signal areas in the ${ }^{29} \mathrm{Si}$ NMR spectrum (Fig. 3a; Table IV) indicate that under the reaction conditions about $40 \%$ of the silane is present as type I groups. ${ }^{29} \mathrm{Si}$ NMR and elemental analysis together yield the following additional percentages: $20 \%$ II, $35 \%$ II', and $5 \%$ III, IV, and V.

After sample 1 was heated at $200^{\circ} \mathrm{C}$ for $1 \mathrm{~h}$ in an $\mathrm{Ar}$ atmosphere, the IR and ${ }^{13} \mathrm{C}$ NMR spectra of the resulting sample 2 indicated that a considerable fraction of the ethoxy groups (see Fig. 2b) had disappeared, while the ${ }^{29} \mathrm{Si}$ spectrum still displayed the same three signals, but with different relative areas (see Fig. 3b; Table IV). This suggests that the following three reactions take place:

$$
\begin{gathered}
\mathrm{I} \rightarrow \mathrm{II}+\mathrm{C}_{2} \mathrm{H}_{5} \mathrm{OH} \\
\mathrm{I} \rightarrow \mathrm{III}+2 \mathrm{C}_{2} \mathrm{H}_{5} \mathrm{OH} \\
\mathrm{II} \rightarrow \mathrm{III}+\mathrm{C}_{2} \mathrm{H}_{5} \mathrm{OH} .
\end{gathered}
$$

Our results do not allow us to distinguish among these three reactions. The amount of substituted silanols increases by ca. $30 \%$, indicating that the above three reactions constitute the main course of the process upon heating sample 1. However, formation of structures IV and V cannot be excluded.

Treatment of sample 1 as above with water expectedly leads to a complete loss of ethoxy groups (sample 3). This was confirmed with IR and ${ }^{13} \mathrm{C}$ NMR spectroscopy (Fig. 2c). According to the ${ }^{29} \mathrm{Si} \mathrm{NMR}$ spectrum (Fig. 3c), the amount of silanol substitution hardly changes, but the signal near -66 ppm becomes much more important (Table IV). A reaction scheme for the main reactions that might explain these data is

$$
\begin{gathered}
\mathrm{II}^{\prime} * \mathrm{I} \rightarrow \mathrm{I}^{\prime} \rightarrow \mathrm{V} \\
\mathrm{II} \rightarrow \underset{*}{\mathrm{II}^{\prime}} \rightarrow \mathrm{IV} .
\end{gathered}
$$

III

Apparently there is a rather strong preference for reactions between silanes over those between silanes and the surface. This can be concluded from the unchanged substituted surface silanols (Table IV). Interactions between the amino group and silanol moieties, belonging either to the silane group or to the silica surface, are conceivable. Our ${ }^{13} \mathrm{C}$ NMR spectra of samples 1-3 (see Fig. 2) are not very conclusive but a slight broadening of the signal near $26.7 \mathrm{ppm}$ for sample 3 may be construed as supporting the idea of some hydrogen bonding involving the amino group (23). Our ${ }^{29} \mathrm{Si}$ spectra do not permit us to conclude whether the interaction involves silane or surface silanols or both.

When sample 3 is heated at $200^{\circ} \mathrm{C}$ no further changes are found in the IR and ${ }^{13} \mathrm{C} N M R$ spectra (sample 4). The ${ }^{29} \mathrm{Si}$ NMR spectrum indicates a further relative increase of the -66 ppm signal as well as an increase in the amount of silanol substitution from 0.27 to 0.34 (Fig. 3d; Table IV).

Possible reactions compatible with these measurements are

$$
\text { II' } \rightarrow \text { III }
$$


and/or reactions of end groups of $\mathrm{V}$ with the surface. As before, no distinction can be made between the two possibilities; while a small contribution of extended crosslinking cannot be excluded.

\section{c. Derivatization of Silica Gel with APS in Water}

After silylation of silica gel with APS in water, as expected no ethoxy groups could be detected in sample 5 by either IR or ${ }^{13} \mathrm{C}$ NMR spectroscopy. The ${ }^{29} \mathrm{Si}$ NMR spectrum independently points to the absence of type I structures and moreover to a somewhat larger amount of silanol substitution than obtained by reaction in toluene. Obviously, the final product comprises structures of types II', III, IV, and $V$ in unknown ratios, since only two separate signals at $-58 \mathrm{ppm}$ and $-67 \mathrm{ppm}$ were observed (see Table IV).

Heating of sample 5 at $200^{\circ} \mathrm{C}$ does not lead to a significantly increased amount of silanol substitution, but the ratios of the two ${ }^{29} \mathrm{Si}$ NMR signals change. The resulting sample 6 shows a remarkable increase of the signal at $-66 \mathrm{ppm}$. This points to the reaction scheme

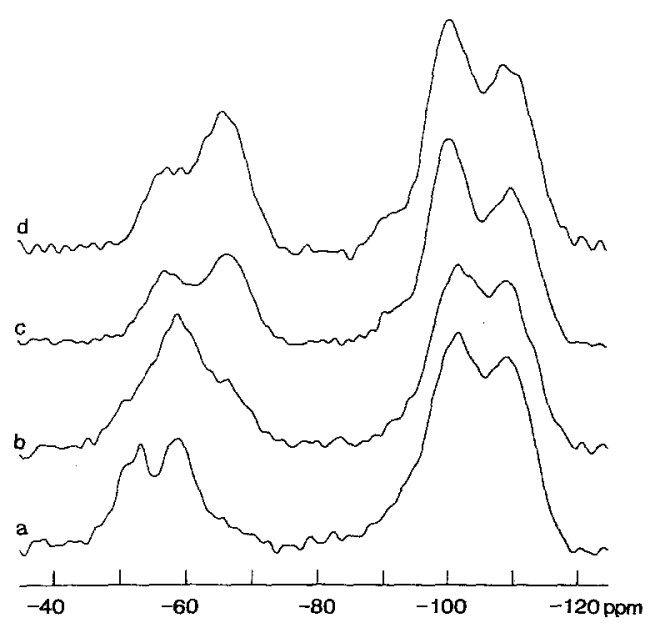

FIG. $3 .{ }^{29} \mathrm{Si}$ CP-MAS NMR spectra: (a) derivatization product of silica gel with APS in toluene, (b) product after heating at $200^{\circ} \mathrm{C}$ in an Ar atmosphere, (c) product after water treatment, and (d) product after treatment as in (c) and heating at $200^{\circ} \mathrm{C}$ in an $\mathrm{Ar}$ atmosphere.

$$
\text { III } * \text { II } \rightarrow \text { IV }
$$

and/or further extension of type V structures.

\section{d. Derivatization of $\mathrm{Cab}-\mathrm{O}$-Sil with APS in Water}

The IR spectrum of sample 7 points to the absence of ethoxy groups. The ${ }^{29} \mathrm{Si}$ NMR spectrum consists of two absorptions at -58 ppm and -66 ppm in approximately a $1: 2$ ratio (see Table IV).

The amount of silanol substitution as estimated from the ${ }^{29} \mathrm{Si}$ NMR spectrum is lower than that for silica gel under the same reaction conditions (sample 5). At first sight this is surprising. Elemental analysis, however, indicates a slightly higher overall conversion of the available hydroxyl groups. This fact and the relative areas in the range -58 to $-66 \mathrm{ppm}$ of the ${ }^{29} \mathrm{Si}$ NMR spectrum point to larger contributions of IV and V to the surface structures than for sample 5 .

Heating of sample 7 leads to a slight increase of silanol substitution and also to a clear decrease of the silanol-to-quaternary silicon ratio. Therefore the main reactions must be

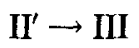

and especially reactions with surface silanols at the endpoints of structure $\mathrm{V}$.

During the reaction of silica gel and APS in toluene, certain types of modification products are formed. Subsequent heating or, more importantly, water treatment is apparently limited in its additional effects. As a consequence heating following water treatment does not appear to produce many extended structures of type $\mathrm{V}$.

If, on the other hand, the synthesis is carried out in water, the silanols will probably react according to Scheme 2 with preferential formation of type $\mathrm{V}$ structures.

The reaction of Cab-O-Sil with APS in water (sample 7) and the subsequent heating process (sample 8) are superficially similar to the corresponding process on silica gel, samples 3 and 4 , respectively, although the increase in degree of silanol substitution after heating differs. This 


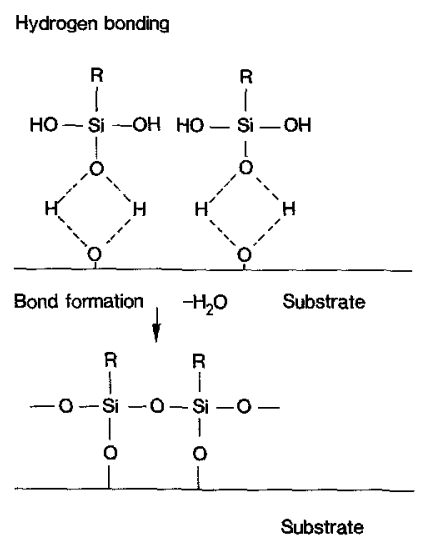

SCHEME 2

may be explained by the fact that the rearrangements upon heating are confined largely to one particle. Moreover, the silanol groups of Cab-O-Sil are more reactive at $100^{\circ} \mathrm{C}$ than the silanol groups of silica gel and subsequent further heating results only in minor changes. Upon reaction of Cab-O-Sil and APS in toluene (sample 9) both the amount of silanol substitution and the product distribution are qualitatively similar to those of silica gel, but with fewer type I structures. These latter structures largely survive the heating (sample 10), probably caused by the larger average distances between reactive sites. The ${ }^{29} \mathrm{Si}$ NMR signal at $-58 \mathrm{ppm}$ has been observed prior to heating and afterward. Probably the main process consists of the conversion of ethoxy groups into hydroxy groups without concomitant formation of large-scale crosslinking. Only small signals are found before and after heating. The conversion of type I to type I' structure can be brought about by water originating from the dehydration of the Cab-O-Sil surface concomitant with formation of siloxane bonds. This also explains the relatively large change in the degree of silanol substitution going from sample 9 to 10 .

Finally, the influence of chain length and reaction temperature on the pattern of attachment to the surface will be described as well as the rearrangements upon water treatment. In view of the above considerations we studied the reactions of 3-methacryloxypropyltrimethoxysilane with silica gel.

\section{e. Derivatization of Silica Gel with MPS in Toluene}

The IR and ${ }^{13} \mathrm{C}$ NMR spectra of sample 11 indicate the presence of considerable amounts of methoxy groups. Cross-polarization characteristics in ${ }^{13} \mathrm{C}$ CP-MAS NMR (Fig. 4) allow only a very rough estimate, amounting to $65 \%( \pm 10 \%)$ of the originally possible two methoxy groups per silane. The ${ }^{29} \mathrm{Si}$ NMR spectrum shows two absorptions near -48 ppm and near $-58 \mathrm{ppm}$. The signal at -48 ppm is assigned to structures of type I (methoxy derivative) as discussed in the preceding sections of this paper. The signal near -58 ppm may be assigned to structure II and underlines once more that silicon atoms bearing hydroxy or methoxy groups are hard to dis-

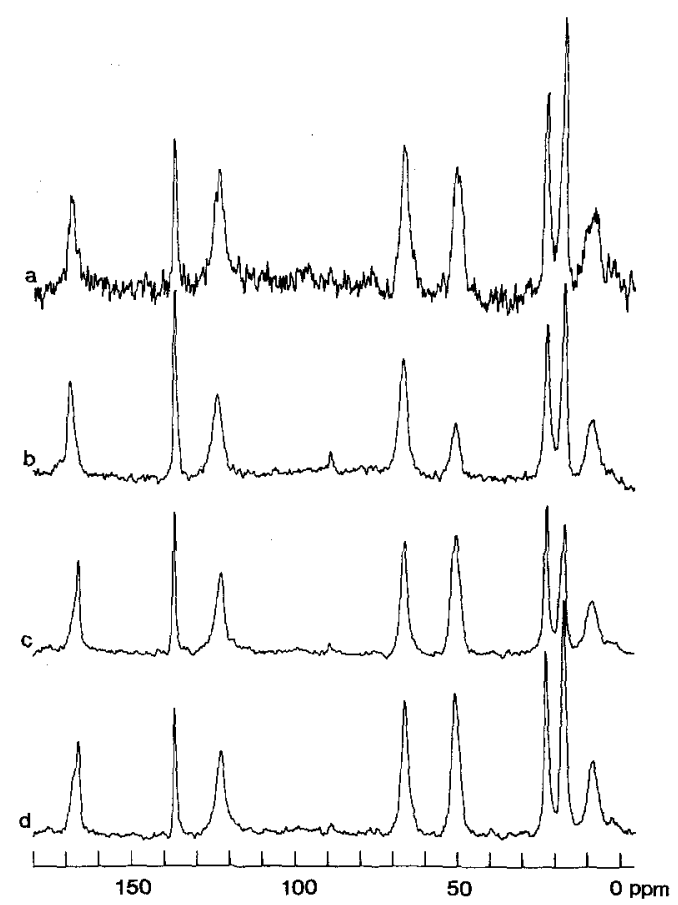

FIG. 4. ${ }^{13} \mathrm{C}$ CP-MAS NMR spectra: (a) derivatization product of silica gel with MPS in toluene, (b) product from (a) after water treatment, (c) derivatization product of silica gel with MPS in biphenyl, (d) product from (c) after water treatment. 
tinguish at the present stage of the technique (2). The relative integrals of both ${ }^{29} \mathrm{Si} \mathrm{NMR}$ signals agree with the above-mentioned percentage of methoxy groups. Elemental analysis and the ${ }^{29} \mathrm{Si}$ NMR spectrum further point to a lower surface coverage than for sample 1 . This can be due to several factors. Besides intrinsic folding of the organic chains, due to their greater lengths, in this case the interaction between keto groups and (probably surface) silanol groups is involved. The IR and ${ }^{13} \mathrm{C}$ NMR spectra contain indications for the latter type of interaction. The IR spectrum shows the carbonyl stretching vibration at $1701 \mathrm{~cm}^{-1}$, with a shoulder at $1717 \mathrm{~cm}^{-1}$. This indicates that most carbonyl groups form hydrogen bonds with $\mathrm{Si}-\mathrm{OH}$ groups (7). In the ${ }^{13} \mathrm{C} \mathrm{NMR}$ spectrum the carbonyl resonance is found at $168.6 \mathrm{ppm}$, clearly downfield from a free carbonyl group in a similar moiety $(24,25)$. The terminal methylene group is also shifted downfield.

After treatment of sample 11 with water (sample 12) it turns out, from the IR and ${ }^{13} \mathrm{C}$ NMR spectra, that about $60 \%$ of the methoxy groups are converted to hydroxy groups (decrease of the $50.0 \mathrm{ppm}$ signal). An extra indication is found in the shift of the $\alpha$-carbon NMR signal from 6.9 to $8.3 \mathrm{ppm}$, resulting in a rather broad signal as a consequence of partial overlap. This is probably caused by the loss of $\gamma$-steric interactions with the methyl part of the methoxy group. The changes in the ${ }^{13} \mathrm{C}$ and ${ }^{29} \mathrm{Si}$ NMR spectra of sample 12 cannot be directly correlated because of the difficulty of distinguishing between $\mathrm{Si}-\mathrm{OCH}_{3}$ and $\mathrm{Si}-$ $\mathrm{OH}$ moieties, but it seems safe to conclude that the majority of the hydrolyzed structures of types I and II ( $\left.=\mathrm{II}^{\prime}\right)$ do not take part in crosslinking processes. Structures of types III, $I V$, and V are only observed in small quantities. The -66 ppm signal contributes to no more than about $10 \%$ in both cases. The reason for this might be found in intramolecular chain reactions of the type $-\mathrm{C}=\mathrm{O}---\mathrm{HO}-\mathrm{Si}$ taking place together with the already mentioned chain-surface interactions.

\section{f. Derivatization of Silica Gel with MPS in Biphenyl}

The influence of the higher reaction temperature is evident (Table II). This is supported by the ${ }^{29} \mathrm{Si}$ NMR spectrum of sample 13, showing a higher degree of silanol substitution, and from elemental analysis, showing a surface coverage, which is ca. $40 \%$ higher than that for sample 11 . Relatively more of the surface silanol groups appear to react to form structures of type III. Both IR and ${ }^{13} \mathrm{C}$ NMR spectra point to the near absence of chain-surface interactions. The IR spectrum shows the main carbonyl vibration at $1719 \mathrm{~cm}^{-1}$, which corresponds to the free $\mathrm{C}=\mathrm{O}$ of MPS. The band at $1719 \mathrm{~cm}^{-1}$ is accompanied by a shoulder at $1701 \mathrm{~cm}^{-1}$. For the ${ }^{13} \mathrm{C}$ NMR chemical shifts of carbonyl and exomethylene moieties see Table III. Water treatment of sample 13 does not cause the loss of more than $10 \%$ of the methoxy groups.

\section{CONCLUSIONS}

Upon carefully controlled reaction of APS with silica gel in dry toluene mainly monodentate and bidentate linkages are formed. Subsequent heating at $200^{\circ} \mathrm{C}$ decreases the monodentate structure, forming tridentate linkages, while crosslinking cannot be excluded. Water treatment leads to a complete loss of the monodentate structures to form crosslinked structures, while bidentate linkages are also present. Curing at $200^{\circ} \mathrm{C}$ results in the formation of more tridentate structures, while extra linkages to surface silanols are possible.

Reaction of APS with silica gel in water yields a product without monodentate structures, but with a considerable contribution of bidentate and tridentate linkages and the formation of crosslinked structures, which become more important on heating at $200^{\circ} \mathrm{C}$.

Reaction of APS with Cab-O-Sil in dry toluene shows a qualitative product distribution analogous to the same reaction with silica gel, while subsequent heating has a different effect; 
i.e., the main course of the reaction concerns conversion of I to I' by means of water, released from the Cab-O-Sil surface.

The reaction product of APS with Cab-OSil in water does not contain monodentate structures, but silane groups with two and especially three siloxane bonds are evident.

Mainly monodentate and bidentate structures are formed upon reaction of MPS with silica gel in dry toluene. After treatment with water it seems that the hydrolyzed product forms only small quantities of tridentate and crosslinking structures, probably caused by the formation of intramolecular hydrogen bonds.

Reaction of MPS with silica gel in biphenyl leads to a much higher degree of silanol substitution with mainly bidentate structures. Water treatment does not essentially change the product composition.

\section{REFERENCES}

1. Plueddemann, E. P., "Silane Coupling Agents." Plenum, New York, 1982.

2. Sindorf, D. W., and Maciel, G. E., J. Amer. Chem. Soc. 105, 3767 (1983).

3. Allum, K., Hancock, R, Howell, I., McKenzie, S., Pitkethly, R., and Robinson, P., J. Organomet. Chem. 87, 203 (1975).

4. Fery, N., Laible, R., and Hamann, K., Angew. Makromol. Chem. 34, 81 (1973).

5. Tundo, P., and Venturello, P., J. Amer. Chem. Soc. 101, 6606 (1979).

6. Chiang, C. H., Ishida, H., and Koenig, J., J. Colloid Interface Sci. 74, 396 (1980).

7. Culler, S., Ishida, H., and Koenig, J., Appl. Spectrosc. 38, 1 (1984).
8. Ishida, H., and Koenig, J., Polym. Eng. Sci. 18, 128 (1978).

9. Chiang, C. H., Liu, N. I., and Koenig, J. L., J. Colloid Interface Sci, 86, 26 (1982).

10. Leyden, D. E., Kendall, D. S., and Waddell, T. G., Anal. Chim. Acta 126, 207 (1981).

11. Leyden, D. E., Kendall, D. S., Burggraf, L. W., Pern, F. J., and DeBello, M., Anal. Chem. 54, 101 (1982).

12. Sindorf, D. W., and Maciel, G. E., J. Amer. Chem. Soc. 102, 7606 (1980).

13. Maciel, G. E., Sindorf, D. W., and Bartuska, V., $J$. Chromatogr. 205, 438 (1981).

14. Sindorf, D. W., and Maciel, G. E., J. Phys. Chem. 86, $5208(1982)$.

15. Sindorf, D. W., and Maciel, G. E., J. Amer. Chem. Soc. 105, 1487 (1983).

16. Sindorf, D. W., and Maciel, G. E., J. Amer. Chem. Soc. 105, 1848 (1983).

17. Bayer, E., Albert, K., Reiners, J., Nieder, M., and Müller, D., J. Chromatogr. 264, 197 (1983).

18. Claessens, H. A., Ven v.d., L.J.M., de Haan, J. W., Cramers, C. A., and Vonk, N., J. High Resolution Chromatogr. Chrom. Commun. 6, 433 (1983).

19. Sindorf, D. W., and Maciel, G. E., J. Amer. Chem. Soc. 103, 4263 (1981).

20. Schraml, J., Chvalovsky, V., Jancke, H., and Englehardt, G., Org. Magn. Reson. 9, 239 (1977).

21. Rudzinski, W. E., Montgomery, T. L., Frye, J. S., Hawkins, B. L., and Maciel, G. E., J. Chromatogr. 323, 281 (1985).

22. Sudhölter, E. J. R., Huis, R., Hays, G. R., and Alma, N. C. M., J. Colloid Interface Sci. 103, 554 (1985).

23. Morishima, I., Yoshikawa, K., Okada, K., Yonezawa, T., and Goto, K., J. Amer. Chem. Soc. 95, 105, (1973).

24. Imashiro, F., Maeda, S., Takegoshi, K., Tesao, T., and Saika, A., Chem. Phys. Lett. 92, 642 (1982).

25. Stothers, J. B., "Carbon-13 NMR Spectroscopy," pp. 287-288. Academic Press, New York, 1972. 